\title{
What I expect of my psychiatrist: the mental health review tribunal
}

\author{
Sir John Wood
}

The proceedings of a mental health review tribunal involve two psychiatrists - one to be found among its members and the other (having care of the patient) who appears before the tribunal as the responsible medical officer (RMO). Both have a very important role to play and the juxtaposition of two psychiatrists guarantees a lively debate at many tribunal hearings.

\section{Psychiatrists as tribunal members}

The structure of the tribunals is well known. They are administered regionally, and each region has a panel of experienced psychiatrists. Each individual tribunal is made up of three members, one randomly taken from each of the three panels: legal, medical and lay, thus ensuring that there is a continual rotation of individuals, an excellent safeguard against 'stolid' panels.

The law requires, and it is a matter of common sense, that its medical member should interview the patient prior to the hearing. He has the right of access to all the patient's medical records from which he may make notes for the hearing. In Section 2 cases, where the order runs for only four weeks, applications have to be dealt with speedily, so the interview may well be on the day of the hearing. In other cases it is usually held a day or two earlier. Practice varies from panel to panel and from case to case, but generally speaking the medical member is expected to report orally, at least in outline, to his colleagues before the hearing starts, drawing attention to any special features which are likely to be of particular importance during the hearing itself. This prepares them for what is to come, but care has to be taken not to over-influence the other members at that stage. As a matter of fairness to the patient, the full report and assessment by the psychiatrist member to his colleagues are normally left until the hearing itself ends, when what is said forms part of the discussion leading to the tribunal's conclusions. This practice allows the other members to form their own preliminary opinions prior to the final consideration and decision.

Although the members of the tribunal have equal status, it is the nature of their work that the specialist opinion of the medical member and the social assessment of the lay member are undoubtedly at the heart of the decision. The legal president's expertise will largely involve ensuring that the rules of law are respected and that any problems which arise regarding this are properly dealt with. The president is also responsible for the conducting of the proceedings themselves. The actual process of making the decision is, of course, a joint responsibility.

The rules governing tribunals require two fundamental assessments from the psychiatrist. The first is to confirm the presence of one of the essential statutory grounds for the order. If they are absent, then the order must be discharged. Errors on this are very rarely made but where a doubt does arise there will be, during the course of the hearing, a thorough discussion with the RMO of this fundamental question. Obviously, the conclusion that none of the statutory grounds is present makes discharge of the order obligatory. The second task is an assessment of the present state of the patient's mental health and the extent to which the patient has insight and shows a genuine willingness to cooperate without the safeguard of the order. This particularly concerns the attitude taken by the patient to continued medication but it also requires assessment of general safeguards of a social nature that are proposed to assist the patient. A lack of insight is fairly easy to judge but there are likely to be promises of future cooperation made which require very careful attention. They are rarely easy to evaluate but are crucial to the decision. 
It is the tribunal psychiatrist's role to give guidance to the tribunal on these matters. Almost always, where discharge of the patient is under consideration, the central concern is the effect of the illness on the patient's insight and willingness to cooperate with appropriate treatment, especially with prescribed medication. Of more general importance is the patient's sincerity and ability to conform to the promises being made. It is further necessary to form a view as to whether the patient, especially if they clearly intend to leave hospital on discharge of the order, is well enough to withstand the everyday pressures that are almost certain to arise and perhaps be aggravated by the residual illness itself. The nature of these pressures and the patient's ability to cope with them, is one of the most important matters, and a tribunal will investigate as far as it possibly can. Although it is a matter of judgement for all three members, the experience of the tribunal psychiatrist will be a great help.

It is sometimes said that a patient would be willing to remain in hospital voluntarily or accept other limitations without the need for the order. Such promises are very difficult to assess, for they are easily given and often broken. The RMO, who knows the patient, will usually have considered this and decided that it is not safe to accept such promises, but the tribunal has the task of evaluating them itself. Similarly, promises to keep in touch with the psychiatrist and continue medication cannot be taken at face value, since once released from the order the temptation not to comply is strong, especially where the side-effects of medication prove to be either unpleasant or restrictive.

It is these questions which underpin the need for the patient to have some prospect of stability in the community. Although the lack of a satisfactory place of residence on discharge or adequate aftercare can never alone justify continuance of an order, it follows that the timing of its removal will undoubtedly be influenced by the need for supportive social surroundings. The professional experience of the medical and lay members of the tribunal are of central importance in guiding the deliberations on these matters.

In cases where discharge of the order is a distinct possibility the decision rarely turns on the simplistic question: is the patient suffering from a statutory mental disability? It will involve a judgement based on a wide range of criteria, on which the opinions of the psychiatrists offer important guidance to the other members. The lay member will of course have a key role to play in assessing the pressures the patient will face in society, and the chairman, in practice rarely having a major legal issue to deal with, has the important role of guiding the panel discussion to an appropriate decision.
It might also be said that experience indicates that although on occasion there may be fierce and healthy debate among the tribunal members, in all but a few cases, as the evidence unravels and is assessed, the decision becomes very much clearer, indeed often inevitable. Although it is difficult for a lawyer not to marvel at the great variation in the approach and style of the tribunal psychiatrists, this does not prevent a remarkable level of professional consistency of judgement. Although it cannot be denied that all three members have equality of esteem, the central question of the patient's disability and its effect on future behaviour could not be satisfactorily answered, in all but a handful of cases, without the essential expertise of the medical member of the tribunal.

\section{Psychiatrists as responsible medical officers}

The powers of the tribunal are, strictly speaking, confined to the continuing need of the statutory order and do not extend to the question of the treatment of the patient. In practice this involvés assessment of the mental disability of the patient, and of the likelihood that the patient will cooperate fully with those who are to provide care and supervision in the community without the safeguard of the order. It is crucial, for instance, to determine whether the patient is likely to honour a pledge to remain in hospital and cooperate as a voluntary patient, or, if expected to leave the hospital, to continue with medication and accept appropriate help and supervision. To assess these matters evidence will be sought from friends who offer support, and from the social worker who will undertake supervision of the patient's welfare in the community. Most are likely to attend the hearing so that their views can be sought. But it is the RMO, whose judgement has led to the continuation of the order and who has the most complete and intimate knowledge of the patient's illness and recent progress, who will provide evidence which will be central in the deliberations of the tribunal.

The tribunal looks for a wide range of essential information from the RMO, accompanied by an explanation of why the order is regarded as necessary.

The tribunal looks to the RMO for:

(a) The preparation for the tribunal of a written, up-to-date assessment of the progress and condition of the patient. It should be prefaced by an account of earlier relevant illnesses and treatment, especially as an in-patient. The 
statement is usually made available to the tribunal some days before it sits. However, in Section 2 cases, which are of necessity scheduled at very short notice, it is appreciated that this may not be possible. In those circumstances a written report submitted on the day of the tribunal, prior to the hearing, is appropriate. In all cases, the RMO will be asked at the hearing to update any reports submitted earlier. It is important also that the patient's principal medical and nursing files are available to the tribunal for reference-they will almost certainly have been consulted by the tribunal doctor prior to interviewing the patient. This information, along with the impressions of the patient gained earlier by the tribunal doctor, who has a statutory duty to examine the patient before the hearing, will be used to determine the most appropriate structure of the hearing itself. The RMOs assessment is essential, not only for its diagnosis and assessment of the progress towards recovery, but also in giving an indication of difficulties and problems that need to be investigated in the course of the hearing. It will also help the tribunal to structure its discussion with the patient during the course of the hearing in as effective a manner as possible.

(b) Attendance at the hearing to give oral evidence to the tribunal and to discuss the questions and concerns that may arise. It is usual for the tribunal administrators to fix the place and time of the hearing so that the RMO can attend in person, although in Section 2 cases, where the hearing has to be fixed quickly, this may not be possible, and so a deputy who has knowledge of the patient and of the RMOs views will be asked to attend. Most tribunals, however, are held at the hospital in which the patient is detained and at which the RMO works, and there is usually some flexibility in fixing a convenient time.

\section{The hearing}

The hearing of a mental health review tribunal differs very markedly, both in structure and approach, from almost all other courts and tribunals. It is as informal as is reasonably possible and the tribunal is able to structure a hearing as it thinks most appropriate, provided that the proper concern for fairness is observed. The disability of some patients makes this flexibility essential, although the prescence of more frequent legal representation has proved to be very useful indeed in ensuring the appropriate structure.

The most striking feature of its procedure is that it takes an inquisitorial rather than an adversarial form. In this it differs from almost all English courts and tribunals and there are very good reasons for this. It is not a 'private' dispute between two parties (the detaining authority and the patient). Paradoxically, the respondent health authority has the position of defending the order solely on what it believes are the best interests of the patient. It is a review, that is to say an independent consideration, of the issues raised by the detention of a mental patient.

The evidence of the patient and the RMO are central to the considerations. The patient, whose liberty is in issue and whose state of health is crucial, is the focal point of the hearing. The RMO, whose judgement will have led to the imposition or continuance of the order (except in restricted cases), is foremost among those whose professional opinions the tribunal will seek. The views of the social worker and of relatives and friends are very important indeed and of the greatest importance where discharge of the order is a possibility.

It is arguably most humane to commence the hearing by talking to the patient who is the subject of the review. Some presidents prefer to start with the RMO, although the logic for this is by no means clear, particularly where the patient has asked for the hearing. However, whether the RMO proceeds or follows the patient, there is little difference in what is required. It is impossible to set out a 'standard form' for the evidence but the essentials are clear enough.

If the diagnosis is in doubt, then plainly this is the first concern of the tribunal and is of central concern to the RMO. 'Labelling' some patients with the appropriate form of mental disorder can be very difficult and such cases can give rise to close consideration, in which the evidence of the RMO is central, and in rare cases that of an independent psychiatrist equally so, for the tribunal has to be satisfied that the basis for the detention is present. In all but a handful of cases, the chief concern is whether there is a continuing need for the order. On this, the evidence and opinions of the RMO are of the greatest importance. They will be tested by questioning by the members of the tribunal and the representative of the patient. Often this will involve a long, somewhat unstructured discussion, very unlike the formal examination and crossexamination to be found in a court of law.

The tribunal itself is a specialist body with three members each bringing personal expertise - legal, psychiatric or social. This means that, unlike a 
court, it is not solely dependent on the evidence put to it and the arguments it has heard. However, it is of the utmost importance, as a result of this difference, that the tribunal ensures that there is a full and open discussion of matters which are likely to affect the ultimate decision. It is important that the patientis asked to give a full, unaided account and explanation as to his or her difficulties, problems, hopes and expectations. As it would be completely wrong formally to examine and crossexamine in the usual fashion a person with a mental disorder or a disability, the tribunal needs to be as certain as possible of the insight and abilities of the patient. It is against the background of this distinctive procedure that the role to the RMO has to be considered.

The members of the tribunal to which the case is assigned can be assumed to have initially no prior knowledge of the case. However, by the time of the sitting, its medical member will have seen and examined the patient, often as recently as on the day of the hearing, so the other members of the tribunal will be up-to-date about the patient. Usually, but not invariably, this information will be given before the hearing commences and certainly it can be assumed that any features which require particular attention by the tribunal will have already been indicated as such to all the members.

The tribunal gives close attention to what the RMO has to say. If the illness is long-standing, the problems that have previously arisen and any pattern of recurrence will form an essential basis of its considerations. Often one of the underlying factors will be non-compliance with previously prescribed medication. The tribunal is certain to be particularly concerned with this aspect, since it is of central importance in judging whether there is now adequate insight to help in justifying the removal of the order. The insight and the likely cooperation by the patient are of great importance and previous behaviour is a helpful indicator. The tribunal is also likely to seek assurances, especially from the family and social workers, that thought has been given to the avoidance of non-compliance.

It is very difficult to generalise, but the concerns of the tribunal as to the psychiatric aspects of the case fall into two groups. It has to be satisfied that the illness has been fully diagnosed and the likely causes of the breakdown identified. It has also to judge that sufficient time has elapsed to enable the appropriate medication and dosage to be determined. Finally, and most difficult, it has to be satisfied that as far as possible all the prudent safeguards against a relapse are in place.

It has to be emphasised that the rules of hearsay, which are familiar to those who attend criminal cases, do not apply in the tribunal which seeks both relevant facts and opinions. Indeed, all relevant facts and opinions are important - the tribunal has the expertise to give the appropriate weight to the evidence of various kinds put to it, so the rules used, especially in criminal courts, are properly not regarded as a necessary safeguard.

Since the RMO does not intend to remove the order, it is important to enquire how the treatment is expected to progress and when it is felt the patient is likely to have recovered to such an extent as to no longer be required to be subject to an order - a question that cannot obviously be answered with precision. The RMO cannot be expected to plan beyond what is reasonably foreseeable, but will usually be able to indicate how it is felt the patient is likely to progress, obviously with no firm guarantees as to the timings. In discussions with the RMO it is usual for a tribunal to leave each of its members to concentrate their questioning upon the area of their own expertise, but there is inevitably a great deal of overlap.

The patient's legal representative will be asked to raise any matters which have not been covered and to supplement what has been said if that is required. Although it is important to have a clear structure to the proceedings, as distinct from a case conference, this should never be allowed to restrict the patient or any witness from saying everything felt to be necessary.

It is to be expected that at the end of the procedure the patient's representative, or the patient if unrepresented, will have the final word with the tribunal. The decision is likely to be reached by the tribunal immediately after the hearing. It is good practice that the $\mathrm{RMO}$ receives it at the same time as the patient so that, if necessary, steps can be taken to explain to the patient what it entails.

\section{General remarks}

There are three further points of interest. They each indicate thoughts that have arisen from long experience of tribunals that particularly concern the role of the RMO. It would be wrong to read them as critical. Just as it is difficult not to worry about the impact of the work of the tribunal on the patient's progress and clinical relationship with the RMO, so there are aspects which give rise to a wider concern.

\section{Pressure to adopt a more adversarial procedure}

It is essential that the proceedings are not allowed to become patently adversarial. Actions may be 
viewed critically and views put forward may be strongly challenged in the course of the hearing unavoidable if the necessary understanding is to be gained. This is particularly sensitive as far at the patient is concerned and may on occasion be uncomfortable for the RMO and other professional witnesses. The tribunal should strive to protect the investigatory nature of the procedure and to control themselves, the patient's advocate and individual witnesses if difficulties arise. The president at each hearing has to be mindful of these responsibilities.

In practice, such tensions, that once were not uncommon, rarely arise. It is an inevitability of the nature of the enquiry that some sharp edges cannot be avoided.

\section{The revolving door}

Although the tribunal has a restricted remit there is often an important feature of the patient's history background which can give rise to considerable uncertainty.

A patient having a long-standing history of psychiatric illness may have had a considerable number of admissions to hospital, often under an order, which have been largely of quite short duration. The tribunal is bound to ask itself in its considerations why such a pattern has occurred and whether it is at least to some extent avoidable.

It is difficult not to generalise, but there are no doubt very many reasons why such a pattern has arisen. The particular features of the individual patient will clearly be of primary importance. Yet there remains some ground for thinking that the inevitable underlying 'tension' between respect for civil liberties, which points to the earliest possible release, and paternalism, which seeks as its primary aim the protection of the patient, is at the root of such a situation. The approach to this dilemma varies considerably, from hospital to hospital, and from year to year. It is difficult to say to what extent the tendency to short stays in hospital has arisen from the prevailing medical opinion at the time as to the success of control by medication or from the undoubted pressure upon resources. The tribunal is, of course, concerned that the restraints of the order are not unnecessarily prolonged. A pattern of recurrent relapses and short stays in hospital raises a doubt as to how the correct balance may be achieved.

\section{Wider aspects of mental illness or disability}

It is common for a tribunal to ask the applicant patient how the time in hospital is being spent and to ask the professional staff to outline the programme that has been evolved to assist the patient's general recovery. Too often, it has to be said, the answer indicates that a well-thought-out programme of constructive activity has been devised, but is not being followed. To a large extent this is a result of the illness which has weakened the patient's enthusiasm and spirit. Often the tribunal is informed that the patient 'was not interested'. Several underlying factors appear to be at work. The patient's illness itself will be one, but so too will an approach which leaves the decision entirely to the patient. No doubt the days when activities could be insisted upon have gone, but the impression cannot be avoided that this has been replaced at most by a low-key request, lacking the necessary encouragement and enthusiasm.

It is wrong to generalise, but a patient whose time is spent without apparent aim is less likely to be able to withstand the pressures outside hospital. An obvious lack of the ability to engage with some interest or activity will be a worrying factor in the consideration of a tribunal, uncertain whether or not to discharge the order. Thus, the central consideration of whether or not the patient will continue with the prescribed medication has to be assessed in a wider context than is sometimes realised.

It may well be that the current pattern of the availability of tribunals is not ideal. That is a matter that will doubtless be looked at in the periodic review that is usual for this type of legislation and cannot be too far in the future. It is most probable that the juxtaposition of semi-formal managers' reviews and tribunal hearings is excessive - it can certainly lead to confusion. It is surely right that the safeguard of an independent review is most important, and as long as it remains constructive and avoids the adversarial nature of most legal procedures it can be integrated in the pattern of good care for the patient. 